\title{
Calcium Peroxide-Containing Polydimethylsiloxane-Based Microwells for Inhibiting Cell Death in Spheroids through Improved Oxygen Supply
}

\author{
Yuya Mizukami, ${ }^{a}$ Yuki Takahashi, ${ }^{a}$ Kazunori Shimizu, ${ }^{b}$ Satoshi Konishi, ${ }^{c}$ \\ Yoshinobu Takakura, ${ }^{a}$ and Makiya Nishikawa*,a,d \\ ${ }^{a}$ Department of Biopharmaceutics and Drug Metabolism, Graduate School of Pharmaceutical Sciences, Kyoto \\ University; 46-29 Yoshidashimoadachi-cho, Sakyo-ku, Kyoto 606-8501, Japan: ${ }^{b}$ Department of Biomolecular \\ Engineering, Graduate School of Engineering, Nagoya University; Furo-cho, Chikusa-ku, Nagoya 464-8603, Japan: \\ ${ }^{c}$ Department of Mechanical Engineering, Graduate School of Science and Engineering, Ritsumeikan University; \\ 1-1-1 Noji-higashi, Kusatsu, Shiga 525-8577, Japan: and ${ }^{d}$ Laboratory of Biopharmaceutics, Faculty of \\ Pharmaceutical Sciences, Tokyo University of Science; 2641 Yamazaki, Noda, Chiba 278-8510, Japan. \\ Received March 31, 2021; accepted July 7, 2021
}

Multicellular spheroids are expected to be used for in vivo-like tissue models and cell transplantation. Microwell devices are useful for the fabrication of multicellular spheroids to improve productivity and regulate their size. However, the high cell density in microwell devices leads to accelerated cell death. In this study, we developed $\mathrm{O}_{2}$-generating microwells by incorporating calcium peroxide $\left(\mathrm{CaO}_{2}\right)$ into polydimethylsiloxane (PDMS)-based microwells. The $\mathrm{CaO}_{2}$-containing PDMS was shown to generate $\mathrm{O}_{2}$ for $3 \mathrm{~d}$. Then, $\mathrm{CaO}_{2}$-containing PDMS was used to fabricate $\mathrm{O}_{2}$-generating microwells using a micro-molding technique. When human hepatocellular carcinoma (HepG2) spheroids were prepared using the conventional microwells, the $\mathrm{O}_{2}$ concentration in the culture medium reduced to approx. $67 \%$ of the cell-free level. In contrast, the $\mathrm{O}_{2}$ generating microwells maintained $\mathrm{O}_{2}$ at constant levels. The HepG2 spheroids prepared using the $\mathrm{O}_{2}$-generating microwells had a larger number of live cells than those prepared using the conventional microwells. In addition, the $\mathrm{O}_{2}$-generating microwells rescued hypoxia in the HepG2 spheroids and increased cell viability. Lastly, the $\mathrm{O}_{2}$-generating microwells were also useful for the preparation of multicellular spheroids of other cell types (i.e., MIN6, B16-BL6, and adipose-derived stem cells) with high cell viability. These results showed that the $\mathrm{O}_{2}$-generating microwells are useful for preparing multicellular spheroids with high cell viability.

Key words oxygen generator; multicellular spheroid; tissue engineering; hypoxia

\section{INTRODUCTION}

Culturing cells under three-dimensional conditions induces more in vivo tissue-like cellular characteristics than culturing cells under monolayer conditions and is expected to be used for tissue models and cell transplantation. ${ }^{1)}$ Multicellular spheroids, which are cell aggregates prepared by culturing cells on non-adhesive surfaces, are typical examples of cells cultured under three-dimensional conditions. ${ }^{2,3)}$ Multicellular spheroids have been used as tumor tissue models ${ }^{4-6)}$ and as formulations for transplantation of islet $\beta$ cells, ${ }^{7)}$ hepatocytes, ${ }^{8)}$ and mesenchymal stem cells, ${ }^{9}$ among others. ${ }^{10)}$

High-quality spheroids for cell transplantation need to be prepared in large quantities. For example, it has been reported that 300000 islets, which are spheroid-like cell aggregates, were required for a single patient to obtain therapeutic effects in patients with type 1 diabetes. ${ }^{11)}$ In addition, spheroid size is one of the factors determining the cellular functions of spheroids $^{12,13)}$; thus, uniformly sized spheroids should be prepared. Microwell devices, in which a number of microwells are placed on a low-adhesive material, such as polydimethylsiloxane (PDMS), are useful for preparing a large number of size-controlled spheroids. We reported previously that uniformly sized spheroids were prepared in large quantities using PDMS-microwell devices. ${ }^{14,15)}$

Spheroids contain densely packed cells, which results in poor oxygen permeability into their core region. ${ }^{16,17)}$ In addition, during the culture of a large number of spheroids using microwell devices, it is predicted that oxygen concentration in the culture medium will decrease because of excess oxygen consumption by cells. Factors, such as poor oxygen permeability and excess oxygen consumption, inevitably induce hypoxia and cell necrosis in the spheroids. Therefore, hypoxic conditions in spheroids should be prevented in order to prepare highly functional spheroids for cell transplantation.

Calcium peroxide $\left(\mathrm{CaO}_{2}\right)$ is an oxygen generator that reacts with water to produce hydrogen peroxide. Then, the hydrogen peroxide decomposes into oxygen and water. ${ }^{18)}$ Coronel et al. reported that PDMS mixed with $\mathrm{CaO}_{2}$ gently and continuously generated oxygen, and the cell viability and insulin secretion of rat islets was improved by culturing them using the $\mathrm{CaO}_{2}$ containing PDMS. ${ }^{19,20)}$ Therefore, we assumed that the $\mathrm{CaO}_{2}$ containing PDMS-microwell can be used to prepare spheroids with high cell viability.

\section{MATERIALS AND METHODS}

Chemicals The PDMS prepolymer (Silpot 184) and curing agent were purchased from Toray-Dow Corning Co., Ltd. (Tokyo, Japan). Dulbecco's modified Eagle's medium (DMEM, low glucose type) and Hank's balanced salt solution (HBSS) were purchased from Nissui Pharmaceutical Co., Ltd. (Tokyo, Japan). Fetal bovine serum (FBS), 5-(and-6)carboxyfluorescein diacetate succinimidyl ester (CFSE), penicillin and streptomycin (PS), and penicillin, streptomycin, and glutamine (PSG) were purchased from Thermo Fisher Scien- 
tific (Waltham, MA, U.S.A.). Trypan blue stain solution was purchased from Nacalai Tesque Inc. (Kyoto, Japan). Trypsin was purchased from Becton Dickinson and Co. (Mansfield, MA, U.S.A.). Mono azo rhodamine (MAR) was obtained from Goryo Chemical (Hokkaido, Japan). DMEM (high glucose type), calcium peroxide, and collagenase (derived from Clostridium histolyticum) were purchased from Sigma-Aldrich (St. Louis, MO, U.S.A.). Monothioglycerol was purchased from FUJIFILM Wako Pure Chemical Corporation (Osaka, Japan). All other chemicals were of the highest grade commercially available.

Cell Culture Human hepatocellular carcinoma HepG2 cells were purchased from ATCC (Rockville, MD, U.S.A.) and cultured in DMEM (low glucose) supplemented with $10 \%$ heat-inactivated FBS, $0.2 \% \mathrm{NaHCO}_{3}$, and PSG. Mouse insulinoma MIN6 cells were kindly provided by Professor Junichi Miyazaki (Graduate School of Medicine, Osaka University, Osaka, Japan) and cultured in DMEM (high glucose) supplemented with $10 \%$ heat-inactivated $\mathrm{FBS}, 0.3 \% \mathrm{NaHCO}_{3}, \mathrm{PS}$, and $0.5 \mathrm{mM}$ monothioglycerol. Mouse melanoma B16-BL6 cells were obtained from RIKEN BRC (Tsukuba, Japan) and cultured in DMEM (low glucose) supplemented with $10 \%$ heat-inactivated FBS, $0.2 \% \mathrm{NaHCO}_{3}$, PSG, and $2 \mathrm{~g} / \mathrm{L}$ glucose. The cells were cultured at $37^{\circ} \mathrm{C}$ in a humidified atmosphere containing $5 \% \mathrm{CO}_{2}$.

Animals Six-week-old male ICR mice were purchased from Japan SLC, Inc. (Shizuoka, Japan). All protocols for the animal experiments were approved by the Animal Experimentation Committee of the Kyoto University Graduate School of Pharmaceutical Sciences.

Isolation of Adipose-Derived Stem Cells (ASCs) Fat pads were isolated from the abdominal cavity of ICR mice euthanized by cervical dislocation. The fat pads were minced to $<1-\mathrm{mm}$ pieces in HBSS using forceps and digested in $1 \mathrm{mg} / \mathrm{mL}$ collagenase in HBSS for $90 \mathrm{~min}$ at $37^{\circ} \mathrm{C}$. Then, the digested samples were filtered through a $100-\mu \mathrm{m}$ filter and centrifuged $\left(300 \times \boldsymbol{g}, 5 \mathrm{~min}, 20^{\circ} \mathrm{C}\right)$. The supernatant containing fat cells was discarded and the red blood cells (RBCs) were lysed using RBC lysis buffer $\left(155 \mathrm{mM} \mathrm{NH}_{4} \mathrm{Cl}, 10 \mathrm{mM}\right.$ $\mathrm{KHCO}_{3}, \quad 0.1 \mathrm{mM}$ ethylenediaminetetraacetic acid (EDTA)). After centrifugation $\left(300 \times \boldsymbol{g}, 5 \mathrm{~min}, 20^{\circ} \mathrm{C}\right)$, the precipitates were seeded in culture plates, and non-adherent cells were removed one day after seeding. The adherent cells were used as ASCs.

Measurement of $\mathrm{O}_{2}$ Generation from $\mathrm{CaO}_{2}$-Containing PDMS $\mathrm{CaO}_{2}$ was mixed with PDMS prepolymer containing $10 \%$ curing agent at $0,5,15$, and $25 \%$ of $\mathrm{CaO}_{2}$, and $1 \mathrm{~g}$ of this mixture was poured into a $50-\mathrm{mL}$ tube and cured at $60^{\circ} \mathrm{C}$ for $2 \mathrm{~h}$. Then, $5 \mathrm{~mL}$ of water was added to the solidified $\mathrm{CaO}_{2}-$ containing PDMS and the concentration of $\mathrm{O}_{2}$ in the liquid was measured using a dissolved oxygen meter (Multimeter HQ30d, TOADKK Co., Ltd., Tokyo, Japan) at 1, 2, 4, 6, 8, $12,24,48$, and $72 \mathrm{~h}$ after the addition of water. The liquid was replaced with fresh water every $24 \mathrm{~h}$.

Fabrication of $\mathrm{O}_{2}$-Generating Microwells $\mathrm{O}_{2}$-Generating microwells were fabricated as described in our previous manuscript ${ }^{14)}$ with some modifications. In brief, the PDMS prepolymer containing $\mathrm{CaO}_{2}(0,5,15$, and $25 \%)$ and the curing agent were poured into the microwell mold and cured at $60^{\circ} \mathrm{C}$ for $2 \mathrm{~h}$. Then, the sheet containing the $\mathrm{O}_{2}$-generating microwells was peeled off and 34-mm-diameter circles (800 microwells/circle) were punched out. The $\mathrm{O}_{2}$-generating microwell circles were placed into the wells of 6 -well plates with $1 \mathrm{~mL}$ PDMS prepolymer containing $10 \%$ curing agent. Following incubation at $60^{\circ} \mathrm{C}$ for $2 \mathrm{~h}$ for anchorage to prevent from floating of microwell circle, the system was sterilized by irradiation with UV light $(253.7 \mathrm{~nm})$ for $1 \mathrm{~h}$.

Preparation of Spheroids Cells harvested using $0.25 \%$ (w/v) trypsin-EDTA solution were resuspended in culture medium at a cell density of $2.5 \times 10^{6}$ cells $/ 3 \mathrm{~mL}$. Then, $2.5 \times 10^{6}$ cells were added on each $\mathrm{O}_{2}$-generating microwell circle that had been placed in the 6 -well plates and incubated at $37^{\circ} \mathrm{C}$ in a humidified atmosphere containing $5 \% \mathrm{CO}_{2}$. The culture medium was changed $1 \mathrm{~h}$ after the addition of cells and every $24 \mathrm{~h}$ thereafter. After $72 \mathrm{~h}$ of incubation, the spheroids obtained were used for experiments.

Characteristics of Spheroids The diameter of the spheroids was measured using a microscope with an image analysis system (BZ-X710, KEYENCE, Osaka, Japan). Twenty spheroids were collected using a micropipette and were dispersed using $0.25 \%(\mathrm{w} / \mathrm{v})$ trypsin-EDTA. After staining with trypan blue solution, the number of live cells was measured by counting the unstained cells using microscopy, and the number of live cells in each spheroid was calculated. The cell viability in spheroids could not be calculated because dead cells were hardly liberated from cell debris after dispersion of the spheroids.

Live/Dead Imaging The spheroids were stained with $1 \mu \mathrm{M}$ CFSE and $5 \mu \mathrm{g} / \mathrm{mL}$ propidium iodide in Opti-MEM $\left(30 \mathrm{~min}, 37^{\circ} \mathrm{C}\right)$. After washing three times with phosphatebuffered saline (PBS), the spheroids were fixed with $4 \%$ paraformaldehyde in phosphate buffer (Nacalai Tesque, Inc.) overnight at $4{ }^{\circ} \mathrm{C}$. After fixing, the spheroids were optically cleared using the ScaleS method. ${ }^{21)}$ In brief, the spheroids were incubated with ScaleSQ(0) $(22.5 \%$ (w/v) D[-]-sorbitol and $9.1 \mathrm{M}$ urea [pH 8.4]) for $24 \mathrm{~h}$ at $4{ }^{\circ} \mathrm{C}$ and then with ScaleS4(0) $(40 \%$ (w/v) $\mathrm{D}[-]$-sorbitol, 10\% (w/v) glycerol, $4 \mathrm{M}$ urea, and $20 \%$ (v/v) dimethyl sulfoxide) for $24 \mathrm{~h}$ at $4{ }^{\circ} \mathrm{C}$. The optically cleared spheroids were observed using confocal fluorescence microscopy (A1R MP microscope, Nikon, Tokyo, Japan).

Estimation of the Hypoxic Environment around Each Spheroid The culture medium of the spheroids was collected every $24 \mathrm{~h}$, and the $\mathrm{O}_{2}$ concentration in the medium was measured using a dissolved oxygen meter. At 1 or $48 \mathrm{~h}$ after addition of cells to the microwells, the culture medium was replaced with fresh culture medium containing $1 \mu \mathrm{M}$ MAR. After incubation for $24 \mathrm{~h}$, the spheroids were dispersed using trypsin-EDTA $(0.25 \%(\mathrm{w} / \mathrm{v}))$ in PBS. The fluorescence intensity of the cells was measured using flow cytometry using a Gallios Flow Cytometer (Beckman Coulter, Miami, FL, U.S.A.), and the mean fluorescence intensity (MFI) was calculated. The data were analyzed using Kaluza software (version 1.0; Beckman Coulter).

Statistical Analysis Differences among multiple groups were statistically evaluated using one-way ANOVA followed by the Tukey-Kramer test. $p$-Values $<0.05$ were considered statistically significant.

\section{RESULTS}

$\mathrm{CaO}_{2}$-Containing PDMS Continuously Generates Oxygen in Water After water was added onto PDMS containing 

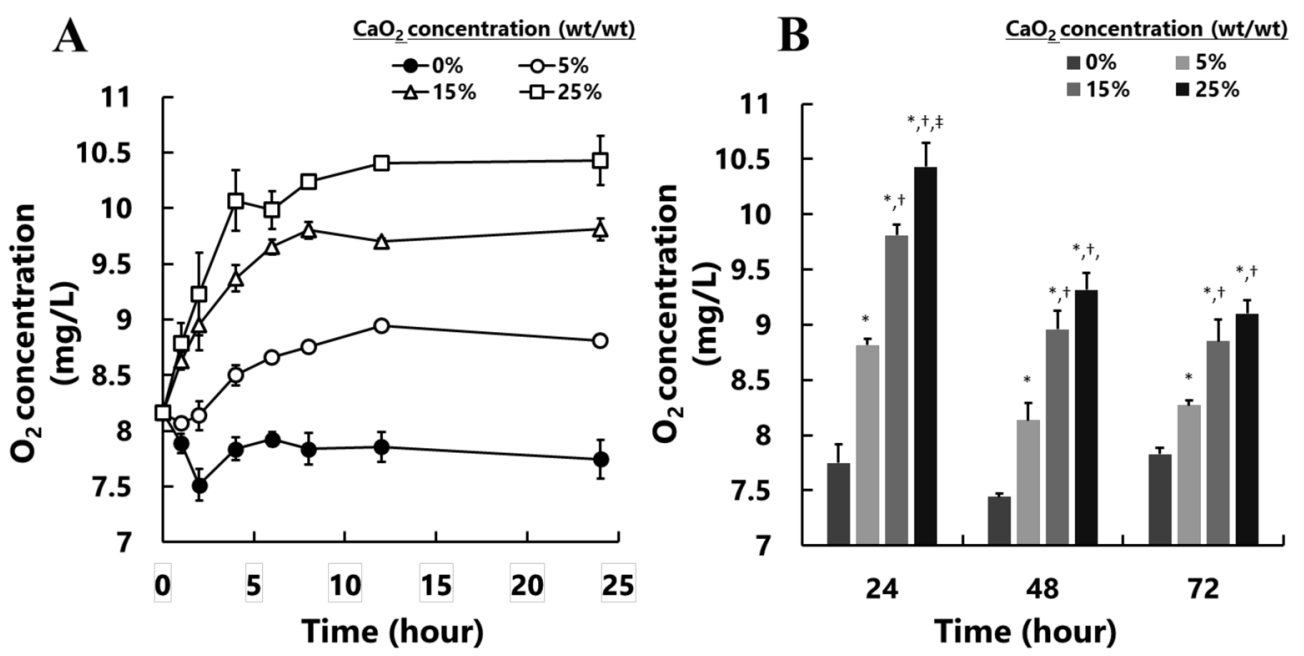

Fig. 1. $\mathrm{CaO}_{2}$-Containing PDMS Slowly Releases Oxygen

(A) $\mathrm{O}_{2}$ release from PDMS containing $0 \%$ (black circle), $5 \%$ (white circle), $15 \%$ (triangle), or 25\% (square) $\mathrm{CaO}_{2}$ for $24 \mathrm{~h}$. Results are expressed as the mean \pm standard deviation of three independent experiments. (B) Repetitive oxygen release from PDMS containing $0,5,15$, or $25 \%$ CaO 2 evaluated at 24,48 , and $72 \mathrm{~h}$. Results are expressed as the mean \pm standard deviation of three independent experiments. ${ }^{*} p<0.05 v s .0 \%,{ }^{\dagger} p<0.05 v s .5 \%,{ }^{\star} p<0.05 v s .15 \%$.

A

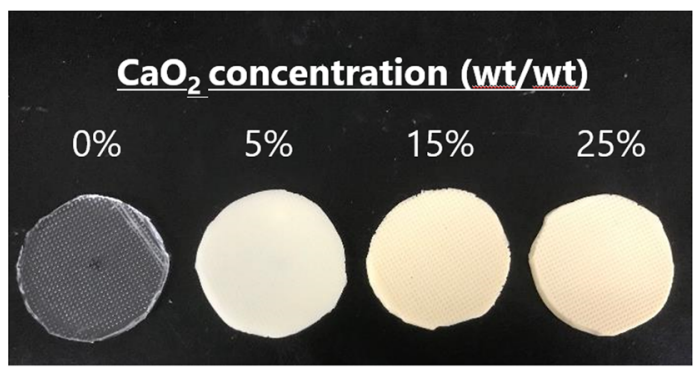

B $\quad 0 \%$

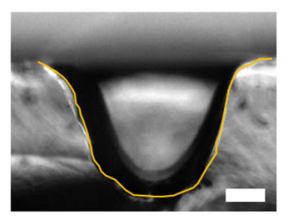

$15 \%$

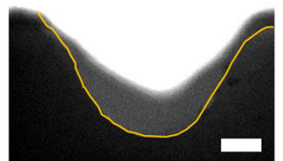

$5 \%$

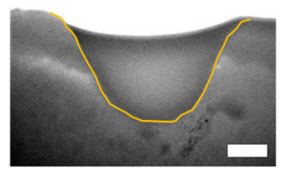

$25 \%$

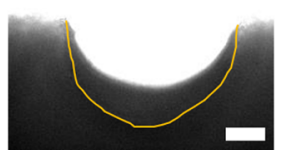

Fig. 2. Microwells Formed Using PDMS Containing Different Amounts of $\mathrm{CaO}_{2}$

(A) Images of $\mathrm{O}_{2}$-generating microwells. (B) Sectional images of $\mathrm{O}_{2}$-generating microwells. Scale bar $=100 \mu \mathrm{m}$. (Color figure can be accessed in the online version.)

$0,5,15$, and $25 \% \mathrm{CaO}_{2}$, which had been cured at the bottom of the tubes, the $\mathrm{O}_{2}$ concentration in the water was measured for $24 \mathrm{~h}$ (Fig. 1A). The $\mathrm{O}_{2}$ concentration increased as the amount of $\mathrm{CaO}_{2}$ increased. Next, to estimate ongoing $\mathrm{O}_{2}$ release, the water was replaced every $24 \mathrm{~h}$ and the $\mathrm{O}_{2}$ concentration was measured $24 \mathrm{~h}$ after each replacement (Fig. 1B). At all time points, the $\mathrm{O}_{2}$ concentration increased as the amount of $\mathrm{CaO}_{2}$ increased. Therefore, PDMS containing $\mathrm{CaO}_{2}$ generated $\mathrm{O}_{2}$ for at least $72 \mathrm{~h}$ after soaking in water.

Fabrication of $\mathrm{O}_{2}$-Generating Microwells $\mathrm{O}_{2}$-generating microwells were fabricated using a micro-molding technique. ${ }^{14)}$ Figure $2 \mathrm{~A}$ shows images of the microwell circles of PDMS containing $0,5,15$, and $25 \% \mathrm{CaO}_{2}$. The translucent PDMS became opaque upon the addition of $\mathrm{CaO}_{2}$. Observation of sectional images confirmed that the $\mathrm{O}_{2}$-generating microwells had microwell structures (Fig. 2B).

$\mathrm{O}_{2}$-Generating Microwells Attenuate the Reduction in Oxygen Concentration during Fabrication of HepG2 Spheroids HepG2 cells were cultured in the $\mathrm{O}_{2}$-generating microwells for $72 \mathrm{~h}$. The $\mathrm{O}_{2}$ concentration in the culture medium was measured every $24 \mathrm{~h}$ before the medium was changed (Fig. 3). Twenty-four hours after the start of incubation using conventional microwells (without $\mathrm{CaO}_{2}$ ), the $\mathrm{O}_{2}$ concentration

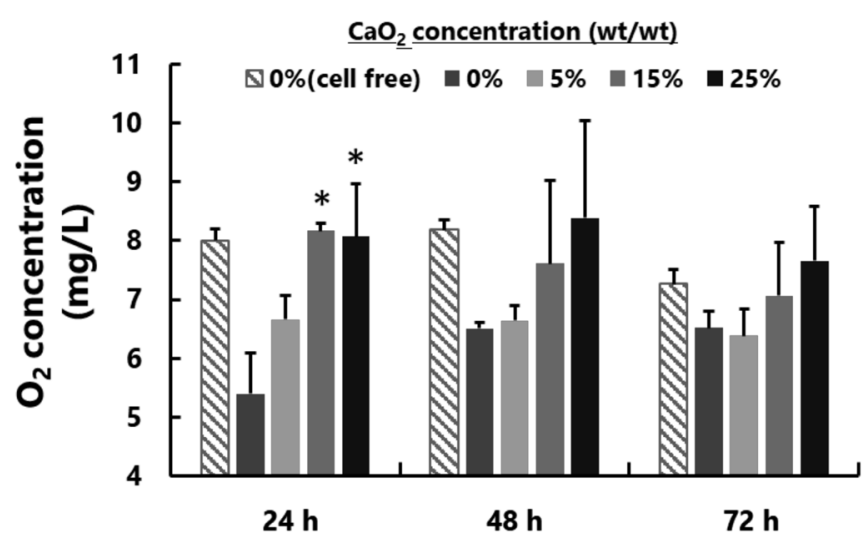

Fig. 3. $\mathrm{O}_{2}$-Generating Microwells Prevent $\mathrm{O}_{2}$ Decrease in the Culture Medium of HepG2 Spheroids

$\mathrm{O}_{2}$ concentration in the culture medium of HepG2 spheroids at 24, 48, and $72 \mathrm{~h}$. Results are expressed as the mean \pm standard deviation of three independent experiments. ${ }^{*} p<0.05$ vs. $0 \%$ (control).

in the culture medium decreased by $67 \%$ in the presence of spheroids compared to that in the cell-free group. In contrast, the $\mathrm{O}_{2}$-generating microwells containing $\mathrm{CaO}_{2}$ at 15 and $25 \%$ attenuated the reduction in $\mathrm{O}_{2}$ concentration. At 48 and $72 \mathrm{~h}$, 
$\mathbf{A}$

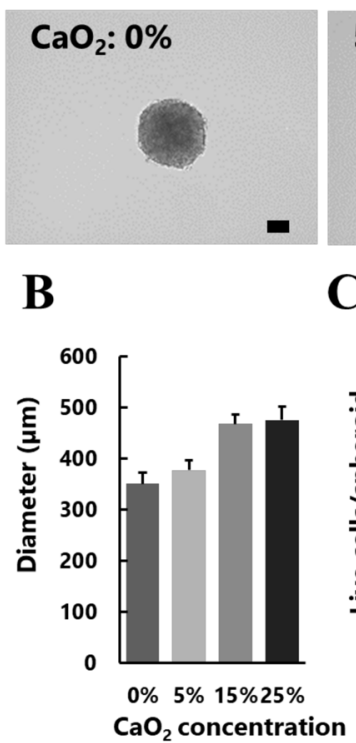

$\mathbf{E}$ (wt/wt)

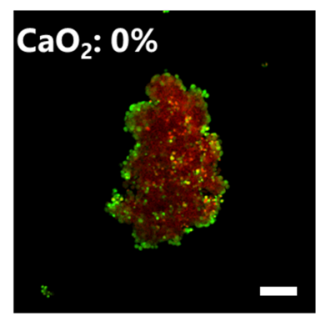

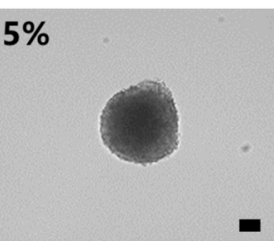

C

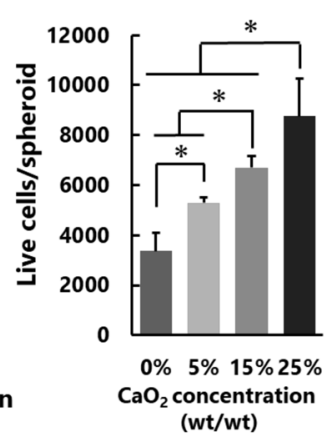

(wt/wt)

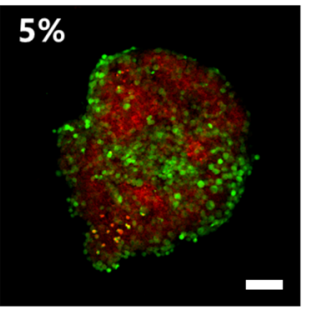

$15 \%$

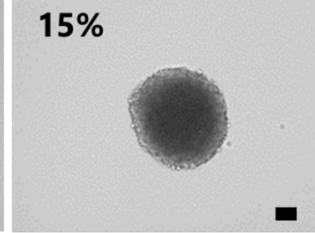

D

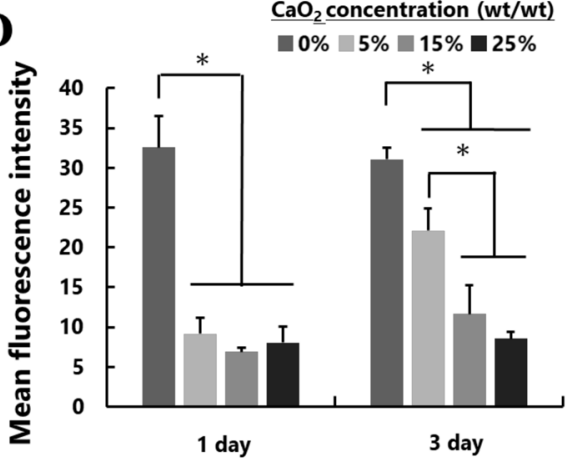

Live cell (CFSE) Dead cell (PI)

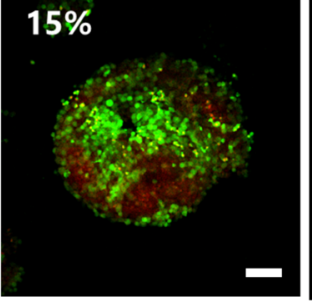

$25 \%$

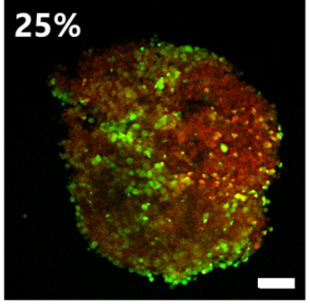

Fig. 4. Improvement in Hypoxic Core Region and Viability of HepG2 Spheroids Using $\mathrm{O}_{2}$-Generating Microwells

(A) Images of HepG2 spheroids fabricated using $\mathrm{O}_{2}$-generating microwells. Scale bars $=100 \mu$ m. (B) Diameter of HepG2 spheroids fabricated using $\mathrm{O}_{2}$-generating microwells. Results are expressed as the mean \pm standard deviation of one hundred measurements. (C) Number of live cells in HepG2 spheroids fabricated using $\mathrm{O}_{2}$-generating microwells. Results are expressed as the mean \pm standard deviation of five measurements. * $p<0.05$. (D) Mean fluorescence intensity of MAR (hypoxia-sensitive fluorescence probe)-treated HepG2 cells in spheroids fabricated using $\mathrm{O}_{2}$-generating microwells. The fluorescence intensity was measured using flow cytometry. Results are expressed as the mean \pm standard deviation of four independent experiments. ${ }^{*} p<0.05 v s .0 \%$ (control). (E) Fluorescence images of HepG2 spheroids fabricated using $\mathrm{O}_{2}$-generating microwells. Live and dead cells were stained with CFSE (green) and propidium iodide (PI, red), respectively. Scale bar $=100 \mu \mathrm{m}$. $(\mathrm{Color}$ figure can be accessed in the online version.)

there was a tendency for an increase in oxygen concentration using the $\mathrm{O}_{2}$-generating microwells, but the differences were not significant.

$\mathrm{O}_{2}$-Generating Microwells Rescue Hypoxia in HepG2 Spheroids and Improve Cell Viability HepG2 spheroids were successfully prepared by culturing HepG2 cells in $\mathrm{O}_{2}$ generating microwells for $72 \mathrm{~h}$ (Fig. 4A). The size of the spheroids increased as the amount of $\mathrm{CaO}_{2}$ mixed with the microwells increased (Fig. 4B). Dispersion of the spheroids with $0.25 \%(\mathrm{w} / \mathrm{v})$ trypsin-EDTA followed by trypan blue staining showed that the number of live cells in the HepG2 spheroids increased as the amount of $\mathrm{CaO}_{2}$ mixed with the microwells increased (Fig. 4C). Next, the $\mathrm{O}_{2}$ status in the HepG2 spheroids was determined using a hypoxia-sensitive probe MAR, which irreversibly becomes fluorescent under hypoxic conditions and is locked into cells. ${ }^{22)}$ The MAR-treated HepG2 spheroids were dispersed, and the fluorescence intensity derived from MAR was measured using flow cytometry (Fig. 4D). The HepG2 cells in spheroids cultured for $1 \mathrm{~d}$ in $\mathrm{O}_{2}$-generating microwells showed lower fluorescence intensity than those cultured in conventional microwells. The HepG2 cells in spheroids cultured for $3 \mathrm{~d}$ in $\mathrm{O}_{2}$-generating microwells showed that the fluorescence intensity decreased as the amount of $\mathrm{CaO}_{2}$ mixed with microwell increased. However, graphical evidence showing the hypoxic status in the core region of the spheroids was not obtained because the converted MAR was leaked out from the cells during the optical clearing process. In addition, the live/dead staining of the optically cleared spheroids showed that some live cells were observed at the core region of the spheroids cultured using $\mathrm{O}_{2}$-generating microwells, whereas few live cells were observed when cultured using control microwells (Fig. 4E). These results suggest that the $\mathrm{O}_{2}$-generating microwells improve the hypoxic state and viability of the cells in the core region of the HepG2 spheroids.

$\mathrm{O}_{2}$-Generating Microwells Improve Cell Viability of Spheroids Prepared Using Various Types of Cells To confirm whether the $\mathrm{O}_{2}$-generating microwells are useful for preparing spheroids of cells other than HepG2, MIN6, B16BL6, and ASC cells were used to prepare spheroids in the $\mathrm{O}_{2}$ generating microwells. The MIN6 spheroids were successfully formed unless $\mathrm{O}_{2}$-generating microwells containing $25 \% \mathrm{CaO}_{2}$ were used (Fig. 5A). MIN6 cells produced spheroids of the largest diameter (Fig. 5B) and containing the highest number of live cells when using $\mathrm{O}_{2}$-generating microwells with $5 \%$ $\mathrm{CaO}_{2}$ (Fig. 5C). The B16-BL6 spheroids were hardly formed 


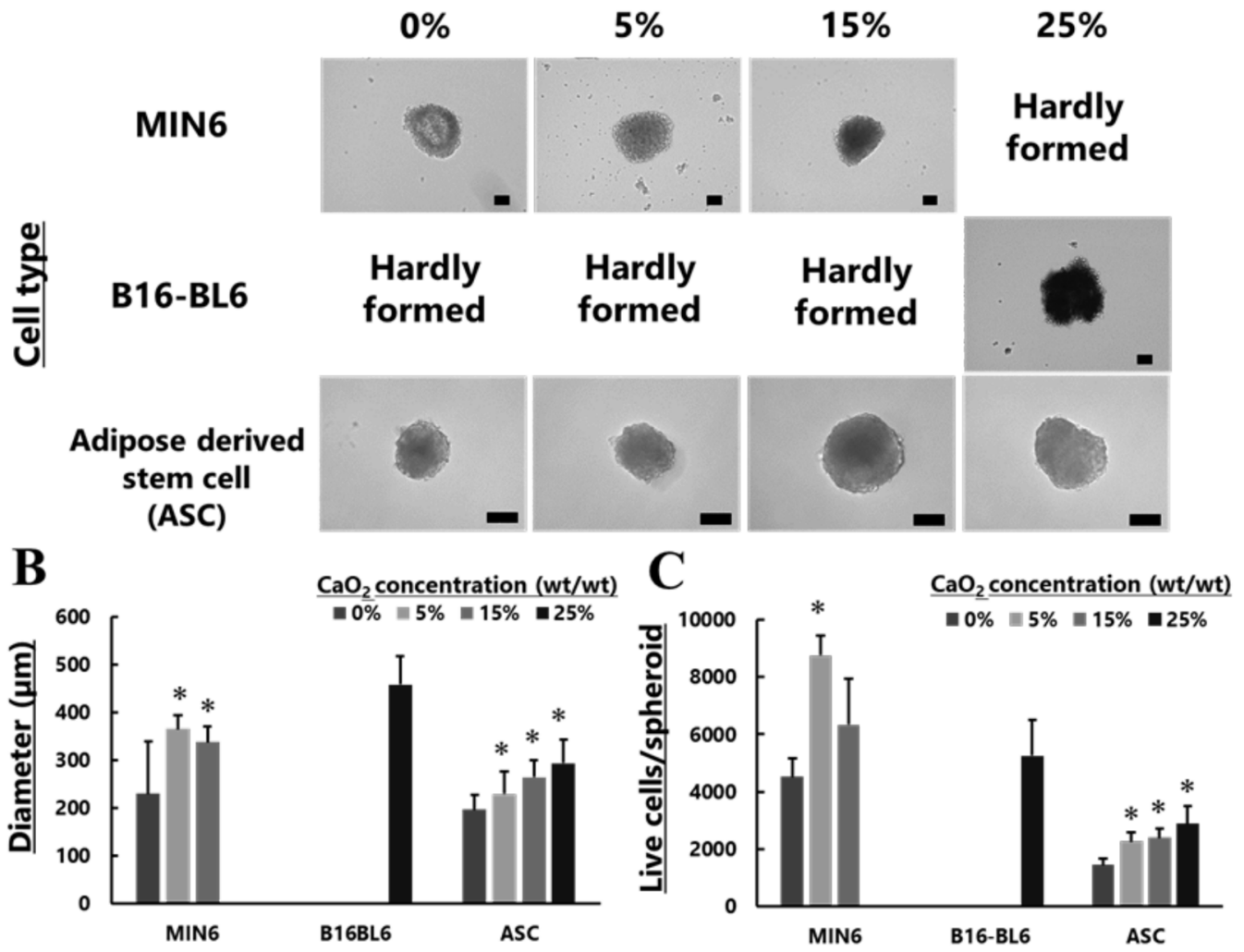

Fig. 5. Spheroid Size and Live Cell Number of Spheroids Increase Using Appropriate $\mathrm{O}_{2}$-Generating Microwells

(A) Images of MIN6, B16-BL6, and ASC spheroids fabricated using $\mathrm{O}_{2}$-generating microwells. Scale bars $=100 \mu \mathrm{m}$. (B) Diameter of MIN6, B16-BL6, and ASC spheroids fabricated using $\mathrm{O}_{2}$ generating microwells. Results are expressed as the mean \pm standard deviation of 100 measurements. $* p<0.05 v s$. $0 \%$ (control). (C) Number of live cells in MIN6, B16-BL6, and ASC spheroids fabricated using $\mathrm{O}_{2}$-generating-microwells. Results are expressed as the mean \pm standard deviation of five measurements. $* p<0.05$ vs. $0 \%$ (control).

when the $\mathrm{O}_{2}$-generating microwells with $0,5,15 \% \mathrm{CaO}_{2}$ were used. However, the B16-BL6 spheroids with high cell viability were formed when the $\mathrm{O}_{2}$-generating microwells containing $25 \% \mathrm{CaO}_{2}$ were used. For ASC cells, the diameter of the spheroids and content of live cells increased as the amount of $\mathrm{CaO}_{2}$ in the microwells increased. These results suggest that $\mathrm{O}_{2}$-generating microwells containing the proper amount of $\mathrm{CaO}_{2}$ are useful for the fabrication of a variety of cell spheroids with high cell viability.

\section{DISCUSSION}

A fabrication technique is required to prepare highly functional multicellular spheroids for tissue models and cell transplantation. Spheroid functionality is closely related to the viability of the cells in spheroids. It is reasonable to speculate that the cell viability and engraftment rate after cell transplantation is correlated with the cell viability under in vitro conditions. In this study, we developed novel $\mathrm{O}_{2}$-generating microwells, which rescued hypoxia-induced cell death in spheroids by continuously supplying $\mathrm{O}_{2}$. In general, hypoxia in the core region of spheroids causes necrosis and decreases cellular function. ${ }^{16,17)}$ Moreover, when a large number of spheroids are prepared using microwell devices, the reduction in $\mathrm{O}_{2}$ concentration in the culture medium caused by excess oxygen consumption worsens hypoxia in the spheroids (Fig. 3). The novel approach of this study showed that the $\mathrm{O}_{2}$ supply to the spheroids using the $\mathrm{O}_{2}$-generating microwells prevented the reduction in $\mathrm{O}_{2}$ concentration under culture conditions (Fig. 3) and rescued cell death in the spheroids (Fig. 4E). These results ensure that a greater number of viable cells can be transplanted when spheroids are prepared using the $\mathrm{O}_{2}$-generating microwells. Coronel et al. reported that the cell viability and insulin secretion of rat islets after transplantation to diabetic rats were improved by culturing the islets on the $\mathrm{CaO}_{2}$-containing PDMS discs. ${ }^{20)}$ Therefore, we think it reasonable to speculate that the cell viability and transplantation rate of the spheroids prepared using the $\mathrm{O}_{2}$-genetrating microwells are higher than those prepared using the conventional microwells. Thus, the $\mathrm{O}_{2}$-generating microwells developed in this study can accelerate studies using multicellular spheroids, including those using in vivo-like tissue models and cell transplantation.

Various approaches to rescue cell death in spheroids have been reported. We and other groups have reported that the incorporation of gelatin microspheres into spheroids increases oxygen permeability and inhibits cell death in the spheroids. $^{23-25)}$ However, these approaches could not solve the problem of decreasing $\mathrm{O}_{2}$ concentration under culture conditions. Other groups have used a bioreactor with a large volume of medium for the preparation of spheroids. ${ }^{26)}$ However, this system could not control the spheroid size. Although the $\mathrm{O}_{2}$ generating microwells would not be expected to increase $\mathrm{O}_{2}$ permeability into the spheroids, hypoxia in the spheroids was improved by using these microwells (Fig. 4D). Perfusion systems were also used to supply $\mathrm{O}_{2}$ for large-scale cell culture. In comparison to the perfusion systems, the $\mathrm{O}_{2}$-generating 
microwells are low in preparation cost, easy to use and require no specialized equipment. Therefore, $\mathrm{O}_{2}$-generating microwells are expected to become a superior approach to minimize cell death in spheroids.

Cells in in vivo tissues are supplied with $\mathrm{O}_{2}$ through blood vessels. On the other hand, cells in spheroids cultured in the $\mathrm{O}_{2}$-generating microwells are supplied with $\mathrm{O}_{2}$ from the surface of the spheroids. The difference in the direction of the $\mathrm{O}_{2}$ supply may have some effects on cell phenotypes. The $\mathrm{O}_{2}$ concentration in the core region of the spheroids could be limitedly increased by the $\mathrm{O}_{2}$ supply from the surface of the spheroids. In this study, the $\mathrm{O}_{2}$-generating microwells increased the $\mathrm{O}_{2}$ concentration in the culture medium during HepG2 spheroids preparation and the viability of HepG2 cells in the core region of the spheroids was improved (Fig. 4). However, the $\mathrm{O}_{2}$ concentration in the core region of spheroids would be lower than that of the peripheral region because $\mathrm{O}_{2}$ was consumed by the cells in the peripheral region before $\mathrm{O}_{2}$ reached to the core region. Therefore, in the hypoxic core region of the spheroids, the phenotypes of the cells could be different from those of the cells in in vivo tissues.

PDMS containing $\mathrm{CaO}_{2}$ slowly and continuously generated $\mathrm{O}_{2}$ for at least $3 \mathrm{~d}$ (Fig. 1). Pedraza et al. reported that a PDMS disc containing $\mathrm{CaO}_{2}$ generated $\mathrm{O}_{2}$ for 2 weeks. ${ }^{19)}$ PDMS is hydrophobic and $\mathrm{CaO}_{2}$ in PDMS would have difficulty reacting with $\mathrm{H}_{2} \mathrm{O}$; this would be one reason for the slow and continuous $\mathrm{O}_{2}$ generation. This system also inhibits the toxicity of $\mathrm{CaO}_{2} \cdot \mathrm{H}_{2} \mathrm{O}_{2}$, the intermediate compound during $\mathrm{O}_{2}$ generation from $\mathrm{CaO}_{2}$, is toxic to cells. ${ }^{27)}$ However, the slow reaction between $\mathrm{CaO}_{2}$ and $\mathrm{H}_{2} \mathrm{O}$ prevented $\mathrm{H}_{2} \mathrm{O}_{2}$ accumulation in the culture medium because $\mathrm{H}_{2} \mathrm{O}_{2}$ is quickly decomposed before accumulation. The $\mathrm{H}_{2} \mathrm{O}_{2}$ concentration in the culture medium was less than $2.5 \mu \mathrm{M}$ (data not shown), which would be barely toxic to HepG2 cells. Excess $\mathrm{O}_{2}$ generation might also damage the cells in spheroids. ${ }^{28)}$ However, the $\mathrm{O}_{2}$ concentration showed no obvious increase when the $\mathrm{O}_{2}$-generating microwells were used (Fig. 3). Therefore, $\mathrm{O}_{2}$-generating microwells can be useful devices for the preparation of highly functional spheroids.

We prepared spheroids of four types of cells, namely, HepG2, MIN6, B16-BL6, and ASC (Figs. 4, 5). The optimal $\mathrm{CaO}_{2}$ concentrations in the $\mathrm{O}_{2}$-generating microwells were found to be dependent on the cell type. When using the $\mathrm{O}_{2}$ generating microwells containing $25 \% \mathrm{CaO}_{2}$, the number of live MIN6 cells in the spheroids decreased, whereas the number of live HepG2, B16-BL6, and ASC cells increased. In particular, B16-BL6 spheroids were formed only when the $\mathrm{O}_{2}$ generating microwells containing $25 \% \mathrm{CaO}_{2}$ were used. When the conventional microwells or the $\mathrm{O}_{2}$-generating microwells containing 5 or $15 \% \mathrm{CaO}_{2}$ were used for the formation of B16-BL6 spheroids, the color of the culture medium changed from red to yellow after $24 \mathrm{~h}$ culture, indicating the $\mathrm{pH}$ of the medium decreased because of the accumulation of lactate. From these results, it was suggested that B16-BL6 cells performed anaerobic respiration because of the lack of $\mathrm{O}_{2}$ and that the cells were under severe hypoxic conditions. The energy produced by the anaerobic respiration is not sufficient for the cells and the resulting low $\mathrm{pH}$ would be toxic to cells. Thus, B16-BL6 spheroids were not formed due to cell death under such conditions. On the other hand, the color of the culture medium remained red when the cells were cultured using the $\mathrm{O}_{2}$-generating microwells containing $25 \% \mathrm{CaO}_{2}$. These results suggest that a sufficient $\mathrm{O}_{2}$ supply by the $\mathrm{O}_{2}$-generating microwells containing $25 \% \mathrm{CaO}_{2}$ prevented severe hypoxiainduced B16-BL6 cell death. On the other hand, hyperoxia produces reactive oxygen species in mitochondria, and they modulate multiple redox-sensitive cellular functions, including apoptosis, survival responses and cellular growth. ${ }^{29,30)}$ In this study, the local $\mathrm{O}_{2}$ concentration at the interface of the microwells and the spheroids was not measured, but spheroids could possibly be exposed to hyperoxia when the $\mathrm{O}_{2}$-generating microwells containing $25 \% \mathrm{CaO}_{2}$ were used. MIN6 spheroid could not be formed in the $\mathrm{O}_{2}$-generating microwells containing $25 \% \mathrm{CaO}_{2}$ because of the toxicity of reactive oxygen species (ROS) produced under hyperoxic conditions. It was reported that hyperoxic exposure increased ROS production and apoptotic cells in rat islets. ${ }^{31)}$ Therefore, when spheroids are prepared using $\mathrm{O}_{2}$-generating microwells, the optimal $\mathrm{CaO}_{2}$ concentration is needed to be checked. The $\mathrm{CaO}_{2}$ concentration in $\mathrm{O}_{2}$-generating microwells can arbitrarily be adjusted, and the concentration could be optimized depending on cell types in future studies.

In general, hypoxia-induced cell death occurs in the core region of spheroids. However, dead or dying cells stained with propidium iodide (PI) or PI and CFSE, respectively, were found not only in the core region, but also in the peripheral region of HepG2 spheroids (Fig. 4E). The limited nutrient supply as well as excessive $\mathrm{O}_{2}$ production near the surface of the $\mathrm{O}_{2}$-generating microwells could cause cells death even in the peripheral region of the spheroids. Most HepG2 spheroids were observed in hemispherical shapes, but not in symmetrical spherical shapes. It can be speculated from these shapes that HepG2 cells settled down to the bottom of the microwells and the basal surface of the spheroids attached directly to the microwell surface. PDMS is a hydrophobic polymer, and the nutrients in the medium are hardly supplied from the basal side of the spheroids. In addition, the local $\mathrm{O}_{2}$ concentration would be very high on the surface of the $\mathrm{O}_{2}$-generating microwells, and this high $\mathrm{O}_{2}$ concentration would result in the production of reactive oxygen species, which could induce cell death even in the peripheral region of the spheroids. Therefore, the results suggest that some cells in the peripheral region of the spheroids underwent cell death.

In this study, we fabricated $\mathrm{O}_{2}$-generating microwells with PDMS containing $\mathrm{CaO}_{2}$. The $\mathrm{O}_{2}$-generating microwells prevented the decrease in $\mathrm{O}_{2}$ concentration in the culture medium and rescued cell death in the spheroids. $\mathrm{O}_{2}$-generating microwells can be useful for fabricating highly functional spheroids.

Conflict of Interest The authors declare no conflict of interest.

\section{REFERENCES}

1) Ravi M, Paramesh V, Kaviya SR, Anuradha E, Solomon FD. 3D Cell culture systems: advantages and applications. J. Cell. Physiol., 230, 16-26 (2015).

2) Cui $X$, Hartanto $Y$, Zhang H. Advances in multicellular spheroids formation. J. R. Soc. Interface, 14, 20160877 (2017).

3) Froehlich K, Haeger JD, Heger J, Pastuschek J, Photini SM, Yan Y, Lupp A, Pfarrer C, Mrowka R, Schleußner E, Markert UR, Schmidt A. Generation of multicellular breast cancer tumor spheroids: com- 
parison of different protocols. J. Mammary Gland Biol. Neoplasia, 21, 89-98 (2016).

4) Rodrigues T, Kundu B, Silva-Correia J, Kundu SC, Oliveira JM, Reis RL, Correlo VM. Emerging tumor spheroids technologies for 3D in vitro cancer modeling. Pharmacol. Ther., 184, 201-211 (2018).

5) Sant $\mathrm{S}$, Johnston PA. The production of 3D tumor spheroids for cancer drug discovery. Drug Discov. Today. Technol., 23, 27-36 (2017).

6) Underhill GH, Khetani SR. Bioengineered liver models for drug testing and cell differentiation studies. Cell. Mol. Gastroenterol. Hepatol., 5, 426-439.el (2017)

7) Kusamori K, Nishikawa M, Mizuno N, Nishikawa T, Masuzawa A, Shimizu K, Konishi S, Takahashi Y, Takakura Y. Transplantation of insulin-secreting multicellular spheroids for the treatment of type 1 diabetes in mice. J. Control. Release, 173, 119-124 (2014).

8) Yap KK, Dingle AM, Palmer JA, Dhillon RS, Lokmic Z, Penington AJ, Yeoh GC, Morrison WA, Mitchell GM. Enhanced liver progenitor cell survival and differentiation in vivo by spheroid implantation in a vascularized tissue engineering chamber. Biomaterials, 34, 3992-4001 (2013).

9) Bhang SH, Lee S, Shin JY, Lee TJ, Kim BS. Transplantation of cord blood mesenchymal stem cells as spheroids enhances vascularization. Tissue Eng. Part A, 18, 2138-2147 (2012).

10) Ong CS, Zhou X, Han J, Huang CY, Nashed A, Khatri S, Mattson G, Fukunishi T, Zhang H, Hibino N. In vivo therapeutic applications of cell spheroids. Biotechnol. Adv., 36, 494-505 (2018).

11) Shapiro AM, Pokrywczynska M, Ricordi C. Clinical pancreatic islet transplantation. Nat. Rev. Endocrinol., 13, 268-277 (2017).

12) Nishikawa T, Tanaka $Y$, Nishikawa M, Ogino $Y$, Kusamori K, Mizuno N, Mizukami Y, Shimizu K, Konishi S, Takahashi Y, Takakura Y. Optimization of albumin secretion and metabolic activity of cytochrome P450 1A1 of human hepatoblastoma HepG2 cells in multicellular spheroids by controlling spheroid size. Biol. Pharm. Bull., 40, 334-338 (2017).

13) Kim SJ, Park J, Byun H, Park YW, Major LG, Lee DY, Choi YS, Shin H. Hydrogels with an embossed surface: an all-in-one platform for mass production and culture of human adipose-derived stem cell spheroids. Biomaterials, 188, 198-212 (2019).

14) Shimizu K, Kusamori K, Nishikawa M, Mizuno N, Nishikawa T, Masuzawa A, Katano S, Takahashi Y, Takakura Y, Konishi S. Poly( $N$-isopropylacrylamide)-coated microwell arrays for construction and recovery of multicellular spheroids. J. Biosci. Bioeng., 115, 695-699 (2013)

15) Nishikawa T, Tanaka Y, Kusamori K, Mizuno N, Mizukami Y, Ogino Y, Shimizu K, Konishi S, Takahashi Y, Takakura Y, Nishikawa M. Using size-controlled multicellular spheroids of murine adenocarcinoma cells to efficiently establish pulmonary tumors in mice. Biotechnol. J., 12, 1600513 (2017).

16) Riffle S, Pandey RN, Albert M, Hegde RS. Linking hypoxia, DNA damage and proliferation in multicellular tumor spheroids. $B M C$ Cancer, 17, 338 (2017).
17) Grimes DR, Kelly C, Bloch K, Partridge M. A method for estimating the oxygen consumption rate in multicellular tumor spheroids. J. R. Soc. Interface, 11, 20131124 (2014).

18) Farris AL, Rindone AN, Grayson WL. Oxygen Delivering Biomaterials for Tissue Engineering. J. Mater. Chem. B., 28, 3422-3432 (2016).

19) Pedraza E, Coronel MM, Fraker CA, Ricordi C, Stabler CL. Preventing hypoxia-induced cell death in beta cells and islets via hydrolytically activated, oxygen-generating biomaterials. Proc. Natl. Acad. Sci. U.S.A., 109, 4245-4250 (2012).

20) Coronel MM, Geusz R, Stabler CL. Mitigating hypoxic stress on pancreatic islets via in situ oxygen generating biomaterial. Biomaterials, 129, 139-151 (2017).

21) Hama H, Hioki H, Namiki $K$, Hoshida $T$, Kurokawa H, Ishidate F, Kaneko T, Akagi T, Saito T, Saido T, Miyawaki A. ScaleS: an optical clearing palette for biological imaging. Nat. Neurosci., 18, $1518-1529(2015)$

22) Piao W, Tsuda S, Tanaka Y, Maeda S, Liu F, Takahashi S, Kushida Y, Komatsu T, Ueno T, Terai T, Nakazawa T, Uchiyama M, Morokuma K, Nagano T, Hanaoka K. Development of azo-based fluorescent probes to detect different levels of hypoxia. Angew. Chem. Int. Ed. Engl., 52, 13028-13032 (2013).

23) Mizukami Y, Moriya A, Takahashi Y, Shimizu K, Konishi S, Takakura Y, Nishikawa M. Incorporation of gelatin microspheres into HepG2 human hepatocyte spheroids for functional improvement through improved oxygen supply to spheroid core. Biol. Pharm. Bull., 43, 1220-1225 (2020).

24) Hayashi K, Tabata Y. Preparation of stem cell aggregates with gelatin microspheres to enhance biological functions. Acta Biomater., 7 , 2797-2803 (2011).

25) Inoo $\mathrm{K}$, Bando $\mathrm{H}$, Tabata $\mathrm{Y}$. Enhanced survival and insulin secretion of insulinoma cell aggregates by incorporating gelatin hydrogel microspheres. Regen. Ther., 8, 29-37 (2018).

26) Frith JE, Thomson B, Genever PG. Dynamic three-dimensional culture methods enhance mesenchymal stem cell properties and increase therapeutic potential. Tissue Eng. Part C Methods, 16, 735-749 (2010).

27) Gholipourmalekabadi M, Zhao S, Harrison BS, Mozafari M, Seifalian AM. Oxygen-generating biomaterials: a new, viable paradigm for tissue engineering? Trends Biotechnol., 34, 1010-1021 (2016).

28) Pisoschi AM, Pop A. The role of antioxidants in the chemistry of oxidative stress: a review. Eur. J. Med. Chem., 97, 55-74 (2015).

29) Gore A, Muralidhar M, Espey MG, Degenhardt K, Mantell LL. Hyperoxia sensing: from molecular mechanisms to significance in disease. J. Immunotoxicol., 7, 239-254 (2010).

30) Lee PJ, Choi AM. Pathways of cell signaling in hyperoxia. Free Radic. Biol. Med., 35, 341-350 (2003).

31) Ma Z, Moruzzi N, Catrina SB, Grill V, Björklund A. Hyperoxia inhibits glucose-induced insulin secretion and mitochondrial metabolism in rat pancreatic islets. Biochem. Biophys. Res. Commun., 443, 223-228 (2014). 